\title{
Peripheral blood RNA gene expression profiling in patients with bacterial meningitis
}

\section{Margit Lill' ${ }^{1}$,Sulev Kõks ${ }^{2,3}{ }^{*}$, Ursel Soomets ${ }^{3,4}$, Leonard C. Schalkwyk ${ }^{5}$, Cathy Fernandes ${ }^{5}$, Irja Lutsar ${ }^{3,6}$ and Pille Taba ${ }^{1 *}$}

${ }^{1}$ Department of Neurology and Neurosurgery, University of Tartu, Tartu, Estonia

2 Department of Physiology, University of Tartu, Tartu, Estonia

${ }^{3}$ Centre for Translational Research, University of Tartu, Tartu, Estonia

${ }^{4}$ Department of Biochemistry, University of Tartu, Tartu, Estonia

${ }^{5}$ Social, Genetic and Developmental Psychiatry Centre, Institute of Psychiatry, King's College London, London, UK

${ }^{6}$ Institute of Microbiology, University of Tartu, Tartu, Estonia

\section{Edited by:}

Hua Lou, Case Western Reserve

University, USA

Reviewed by:

Qingzhong Kong, Case Western Reserve University, USA

Ruth Siegel, Case Western Reserve

University, USA

*Correspondence:

Sulev Kôks, Department of Physiology, University of Tartu, 19 Ravila St, 50411 Tartu, Estonia. e-mail:sulev.koks@ut.ee;

Pille Taba, Department of Neurology and Neurosurgery, University of Tartu, 8 Puusepa St, 51014 Tartu, Estonia.

e-mail: pille.taba@kliinikum.ee
Objectives: The aim of present study was to find genetic pathways activated during infection with bacterial meningitis (BM) and potentially influencing the course of the infection using genome-wide RNA expression profiling combined with pathway analysis and functional annotation of the differential transcription.

Methods: We analyzed 21 patients with BM hospitalized in 2008. The control group consisted of 18 healthy subjects. The RNA was extracted from whole blood, globin mRNA was depleted and gene expression profiling was performed using GeneChip Human Gene 1.0 ST Arrays which can assess the transcription of 28,869 genes. Gene expression profile data were analyzed using Bioconductor packages and Bayesian modeling. Functional annotation of the enriched gene sets was used to define the altered genetic networks. We also analyzed whether gene expression profiles depend on the clinical course and outcome. In order to verify the microarray results, the expression levels of ten functionally relevant genes with high statistical significance (CD177, IL1R2, IL18R1, IL18RAP, OLFM4, TLR5, CPA3, FCER1A, IL5RA, and IL7R) were confirmed by quantitative real-time (qRT) PCR.

Results: There were 8569 genes displaying differential expression at a significance level of $p<0.05$. Following False Discovery Rate (FDR) correction, a total of 5500 genes remained significant at a $p$-value of $<0.01$. Quantitative RT-PCR confirmed the differential expression in 10 selected genes. Functional annotation and network analysis indicated that most of the genes were related to activation of humoral and cellular immune responses (enrichment score 43). Those changes were found in both adults and in children with $\mathrm{BM}$ compared to the healthy controls. The gene expression profiles did not significantly depend on the clinical outcome, but there was a strong influence of the specific type of pathogen underlying BM.

Conclusion: This study demonstrates that there is a very strong activation of immune response at the transcriptional level during $\mathrm{BM}$ and that the type of pathogen influences this transcriptional activation.

Keywords: bacterial meningitis, gene expression profiling, gene networks

\section{INTRODUCTION}

Despite the availability of effective antibiotics, health care and advances in adjunctive therapies, bacterial meningitis (BM) is still one of the top 10 causes of infection related mortality worldwide. Fatality rates as high as $20 \%$ for pneumococcal meningitis and $7 \%$ for meningococcal meningitis are reported. Among the survivors, 30-50\% have permanent neurological sequelae (Weisfelt et al., 2006; Chaudhuri et al., 2008). Therefore, better understanding of the pathophysiological processes and the host's acute inflammatory response could ameliorate treatment and management of BM.
Bacterial invasion into the cerebrospinal fluid (CSF) induces a rapid inflammatory response, which is mediated by the innate immune system. Microglia and astrocytes are equipped with germline-encoded receptors, termed pattern-recognition receptors (PRRs), which have evolved to recognize highly conserved antigens, the so-called PAMPs (pathogen-associated molecular patterns) (Konat et al., 2006). PRRs include the family of Toll-like receptors (TLRs), of which TLR2 is the most important mediator of the inflammatory response to Gram-positive and TLR4 to Gram-negative infection including BM (Koedel et al., 2003; Konat et al., 2006; Neher and Brown, 2007). Many proinflammatory 
cytokines are released early into the circulation in response to sepsis or systemic inflammation. In cases of meningitis, cytokines, and adhesion molecules released by peripheral immune organs in the bloodstream cross the altered blood-CSF barrier and contribute to their CSF levels (Trojano et al., 1996; Fassbender et al., 1997).

The inflammatory response to bacterial invasion as a systemic reaction has been studied in clinical trials investigating sepsis on numerous occasions. The prevailing theory is that the host's response during sepsis, and likely also in BM, represents a pathological inflammatory response and therefore causes more damage than the pathogen itself (Bone et al., 1992; Stone, 1994; Warren, 1997; Hotchkiss and Karl, 2003; Deisenhammer et al., 2006). However, it is not known whether this pathological inflammatory response is triggered by transcriptional changes and whole genome expression profiling, to the best of our knowledge, has not been performed in BM patients to date.

The aim of our study was to identify up- or downregulated transcriptional pathways during the acute phase of BM in RNA extracted from whole blood using whole genome transcriptional profiling combined with pathway analysis and functional annotation. In addition, we analyzed the possible factors (type of pathogen and outcome of the disease) associated with the gene expression profile in patients with BM.

\section{METHODS}

\section{STUDY PARTICIPANTS}

The study was conducted in the Tallinn Children's Hospital, the North Estonian Medical Centre, the Tartu University Hospital, the West Tallinn Central Hospital and the East Tallinn Central Hospital between the 1st of January and the 31st of December 2008 and included 21 patients with culture proven BM and 18 healthy controls. The healthy control group consisted of medical personnel and was free of any acute infection and had not taken any antibiotics within the month prior to blood sampling. BM was diagnosed if in addition to clinical signs of BM, there was a positive CSF culture of meningitis causing bacteria and/or positive blood culture in presence of CSF pleocytosis $\geq 10 \times 10^{6}$ cells/L and/or positive CSF latex agglutination test with pleocytosis $\geq 500 \times 10^{6}$ cells/L. On admission, all patients underwent a full clinical laboratory screening including a head computed tomography (CT). All microbiological analyses were performed according to the Clinical and Laboratory Standards Institute (CLSI) criteria in the local hospital laboratories.

The patients' outcome was evaluated by a neurologist at discharge from the hospital as favorable (normal, 13 patients) or poor outcome (with different complications, six patients), based on objective neurologic examination. Neurologic sequelae included cranial nerve disorders, paresis, ataxia, aphasia, cognitive impairment, apallic state, and epileptic seizures (Table 1). In two cases, the patients died following infection with BM.

Table 1 | Characteristics of the study population.

\begin{tabular}{|c|c|c|c|c|c|c|c|c|}
\hline \multirow[t]{2}{*}{ ID } & \multirow[t]{2}{*}{ Age } & \multirow{2}{*}{$\begin{array}{l}\text { Previous } \\
\text { antibiotics }\end{array}$} & \multicolumn{4}{|c|}{ Laboratory values } & \multirow{2}{*}{$\begin{array}{l}\text { Causative } \\
\text { organism }\end{array}$} & \multirow[t]{2}{*}{ Outcome } \\
\hline & & & $\begin{array}{l}\text { Blood WBC } \\
\left(10^{9} \text { cells } / L\right)\end{array}$ & CRP(mg/L) & $\begin{array}{l}\text { CSF WBC } \\
\left(10^{9} \text { cells } / L\right)\end{array}$ & $\begin{array}{l}\text { CSF } \\
\text { Protein g/L }\end{array}$ & & \\
\hline M028 & 22 days & No & 8.7 & 147 & 13.4 & 2.1 & S. agalactiae & Epileptic syndrome \\
\hline M039 & 17 days & No & 4.1 & 87 & 5.1 & 2.5 & E.coli & Normal \\
\hline M031 & 55 years & No & 8.1 & 219 & 1.5 & 10.1 & S. pneumoniae & Died \\
\hline M032 & 75 years & Yes & 21.8 & 251 & 7.7 & 1.7 & S. pneumoniae & Spastic tetraparesis \\
\hline M027 & 52 years & No & 32.2 & 77 & 0.3 & 7.5 & S. pneumoniae & Aphasia, right spastic hemiparesis \\
\hline M022 & 54 years & No & 9.6 & 171 & 1.2 & 2.6 & S. pneumoniae & Normal \\
\hline M041 & 46 years & No & 26.3 & 5 & 0.07 & 0.5 & S. pneumoniae & Died \\
\hline M046 & 13 years & No & 18.6 & 109 & 4.6 & 2.3 & S. pneumoniae & Normal \\
\hline M040 & 73 years & No & 18.4 & 231 & 1.8 & 1.8 & L. monocytogenes & Normal \\
\hline M029 & 37 years & Yes & 24.2 & 197 & 2.3 & 2.0 & S. pneumoniae & Normal \\
\hline M004 & 57 years & No & 13.4 & 63 & 4.5 & 2.7 & H. influenzae & Normal \\
\hline M014 & 58 years & No & 9.7 & 54 & 2.3 & 9.8 & S. pneumoniae & $\begin{array}{l}\text { Cognitive dysfunction, anisocoria, } \\
\text { left spastic hemiparesis }\end{array}$ \\
\hline M023 & 70 years & Yes & 11.4 & 174 & 4.3 & 6.6 & S. pneumoniae & Normal \\
\hline M047 & 75 years & No & 34.6 & 146 & 0.04 & 0.6 & S. pneumoniae & Cognitive dysfunction \\
\hline M036 & 17days & No & 2 & 105 & 0.2 & 6.9 & S. agalactiae & Normal \\
\hline M042 & 71 years & No & 20.4 & 421 & 0.3 & 1.5 & S. pneumoniae & Normal \\
\hline M025 & 47 years & No & 5.8 & 285 & 1.1 & 0.4 & N. meningitidis $C$ & Facial nerve paresis, ataxia \\
\hline M012 & 6 years & No & 4.3 & 19 & 0.06 & 2.9 & S. pneumoniae & Normal \\
\hline M002 & 7 years & No & 21.9 & 109 & 1.7 & 4.6 & N. meningitidis & Normal \\
\hline M006 & 55 years & No & 11.2 & 321 & 3.4 & 5.8 & S. pneumoniae & Normal \\
\hline M038 & 60 years & No & 16.2 & 15 & 0.7 & 7.4 & S. pneumoniae & Normal \\
\hline
\end{tabular}


Additional comparisons were made in order to assess whether there was a relationship between gene expression profiles and the specific pathogens mediating BM and/or the clinical outcome in the patients. Comparisons were made between three pathogen groups-(A1) pneumococci, (A2) other bacteria and (A3) controls. Clinical outcome was divided into (B1) favorable outcome without sequelae, (B2) poor outcome with neurologic sequelae or death and (B3) healthy controls.

\section{SAMPLE COLLECTION AND RNA PREPARATION}

For RNA expression analysis, $6 \mathrm{ml}$ blood was collected via venipuncture into Tempus tubes (Applied Biosystems, Foster City, USA) within $48 \mathrm{~h}$ of admission, and stored first at $-20^{\circ} \mathrm{C}$ for a maximum of 3-4 months, then transported in dry ice. After thawing, RNA was extracted from whole blood according to the manufacturer's protocol (Applied Biosystems PN 4379228C). Alpha and beta globin mRNA was depleted with the GlobinClear Whole Blood Globin Reduction kit (Ambion, Austin, USA). The quality of RNA was checked with a Bioanalzer 2100 (Agilent, Santa Clara, USA) and gene expression profiling was performed with GeneChip Human Gene 1.0 ST Arrays (Affymetrix, Santa Clara, USA), which can measure the transcription of 28,869 genes.

\section{MICROARRAY HYBRIDIZATION AND ANALYSIS}

The RNA was labeled using the Affymetrix GeneChip Whole Transcript (WT) Sense Target Labeling Assay (Affymetrix, Santa Clara, USA). This assay is designed to generate amplified and biotinylated sense-strand targets from the entire expressed genome without bias. Briefly, double-stranded complementary DNA (cDNA) was synthesized from $300 \mathrm{ng}$ of total RNA by reverse transcription using random hexamers tagged with a T7 promotor primer sequence. The double-stranded cDNA was subsequently used as a template and amplified by T7 RNA polymerase producing several copies of antisense complementary RNA (cRNA). In the second cycle of cDNA synthesis, random hexamers were used to prime reverse transcription of the cRNA from the first cycle to produce single-stranded DNA in the sense orientation. This DNA was fragmented with a combination of uracil DNA glycosylase (UDG) and apurinic/apyrimidinic endonuclease 1 (APE 1). DNA was labeled by terminal deoxynucleotidyl transferase (TdT) and hybridization was performed according to the manufacturer's protocol. The arrays were subsequently washed, stained with phycoerythrin streptavidin and scanned according to standard Affymetrix protocols. Images were processed using the Affymetrix Microarray Suite 5.0 Expression Console and image quality subsequently assessed. The processed data files were further analyzed using Bioconductor affy and limma packages. Gene expression data (.cel files) and study design information has been uploaded to the public database Gene Expression Omnibus (accession number GSE40586).

\section{QUANTITATIVE REAL-TIME PCR (qRT-PCR) ANALYSIS}

In order to verify the microarray results, genes from the gene expression profiling were sorted according to the degree of statistical significance of the differential expression. Ten genes with the lowest $p$-values were selected and further analyzed with qRT-PCR: CD177, IL-1R2, IL-18R1, IL-18RAP, OLFM4, TLR5, CPA3, FCER1A, IL5RA, and IL7R. RNA was converted into cDNA using High Capacity cDNA Synthesis kit from Applied Biosystems (4368814). TaqMan assays and Gene Expression Master mix was used for the qRT-PCR reaction generated in the SDS $7900 \mathrm{HT}$ system (Applied Biosystems, CA, USA).

\section{FUNCTIONAL ANNOTATION OF DIFFERENTIALLY EXPRESSED GENES}

The Functional Analysis of a gene network is used to identify the biological functions that are most significantly related to the molecules in the network. To define the functional networks of differentially expressed genes, data was analyzed by using the Ingenuity Pathway Analysis (IPA, Ingenuity Systems, $w w w . i n g e n u i t y . c o m)$ that calculates a significance score (network score) for each network. This score indicates whether the likelihood that the assembly of a set of focus genes in a network could be explained by random chance alone (e.g., score of 2 indicates that there is a chance of 1 in 100 that the focus genes are together in a network due to random chance). A data set containing the Affymetrix probeset identifiers and their corresponding fold change $(\log 2)$ values were uploaded into the IPA software. Each gene identifier was mapped to its corresponding gene object in the Ingenuity Pathways Knowledge Base to identify molecules whose expression was significantly differentially regulated (focus genes or Networks Eligible molecules). These focus genes were overlaid onto a global molecular network developed from information contained in the Ingenuity Knowledge Base. Networks of these focus genes were then algorithmically generated based on their connectivity.

A network is a graphical representation of the molecular relationships between genes or gene products, which are represented as nodes, and the biological relationship between two nodes is represented as an edge (line). All edges are supported by at least one reference from the literature, or from canonical information stored in the Ingenuity Pathways Knowledge Base.

\section{STATISTICAL ANALYSIS}

The normalized, background subtracted and modeled expression (Robust Microarray Analysis, RMA) data was further analyzed using Bayesian model moderated $t$-test implemented in the Bioconductor limma package of the statistical software R (http:// www.r-project.org/) (Smyth, 2004). False Discovery Rate (FDR) was used to adjust $p$-values and to correct for the multiple testing issues (Storey and Tibshirani, 2003). Comparisons between the groups by pathogens and clinical outcome were performed, using general linear models of analysis of variance (ANOVA), to test the effect of these factors on gene expression pattern. Sample comparisions for the qRT-PCR reaction data were made using Welch's $t$-test.

The Ethics Review Committee on Human Research of the University of Tartu approved the study. All subjects or their legal representatives signed the informed consent.

\section{RESULTS}

The details of study patients are presented in Table 1. There were 21 patients (median age 54 years, IQR 13, 60; 12 males), 
and 18 healthy controls (median age 54 years, IQR 47, 60; 5 males). Two patients died, neurological sequelae were observed in six patients, and the remaining 13 patients had a normal outcome. Altogether 14 patients had a pneumococcal infection, two patients had a group B streptococcus (GBS) infection, and another two patients had meningococcal meningitis. Escherichia coli, Haemophilus influenzae, and Listeria monocytogenes were found in one patient.

\section{GENOME-WIDE EXPRESSION PROFILING}

Comparison of the blood RNA samples isolated from BM patients and healthy controls revealed distinct gene expression profiles. Altogether 5500 genes out of the analyzed 28,869 genes showed statistically significant differential expression at the FDR adjusted $\mathrm{p}$-values $\leq 0.01$. Relative differences in the expression signal (fold change or $\log \mathrm{FC}$ ) between these two groups were of moderate effect size. In the BM patients, 47 genes were up-regulated more than 1.5 fold and 93 down-regulated more than 1.5 fold, compared to controls. In addition, the high B-statistics values for the list of genes were indicative of genuine biological differences between these groups (Table 2). As it appears from the gene annotations, most of these genes were related to immune regulation and the anaphylactic response (e.g., FCER1A, CPA3, MS4A2;

Tables A1, A2).

\section{GENE EXPRESSION PATTERN BM vs. CONTROLS}

Heatmap (Figure 1) and a volcano plot (Figure 2) illustrate the general gene expression pattern in relation to the main factor-diagnosis of BM. The heatmap indicates a good clustering of samples according to whether the infection was present or absent. There is a clear distinction between these two groups and the gene expression profiles were able to discriminate between the two main groups (Figure 1). The volcano plot illustrates a high number of statistically significant differences $(p<10 \mathrm{e}-06$ is the equivalent for Bonferroni corrected $p<0.05)$ (Figure 2). Moreover, the ratio of the differential expression (fold change, illustrated in the abscissa of the volcano plot) is also quite remarkable. Therefore, there was very good correlation between the fold change differences and p-values (i.e., genes with a large fold change difference also had a low $p$ value in the group-wise comparison). Two vertical axes denote the position of a 1.5 and -1.5 fold change difference in the gene expression profiles between disease cases and controls (Figure 2).

In Table 1, the patients are lined up the same order as in the heatmap (Figure 1). With two exceptions, the BM patients and controls are clearly separated as they have very distinct gene expression profiles. The two exceptions clustering within controls (M028 and M039) were both neonates one with E. coli and the other with GBS meningitis.

Additional statistical modeling was performed to assess whether the type of pathogen or the outcome of the disease influenced the gene expression profiles measure in the patient group. Two separate linear models in which the gene expression differences were analyzed for the general effect of clinical outcome [R code: design $\leftarrow$ model.matrix $(\sim 0+$ eset\$outcome $)]$ or for the general effect of pathogen $[\mathrm{R}$ code: design $\leftarrow$ model.matrix $(\sim 0+$ eset\$bacteria) $)$. Subjects were allocated to one of three pathogen groups: infected with $S$. pneumoniae; infected with other pathogens; controls (non-infected). After general modeling

Table 2 | Twenty most significantly up- or down-regulated genes.

\begin{tabular}{|c|c|c|c|c|c|c|c|c|}
\hline Probeset & Sym & $\operatorname{LogFC}$ & AveExpr & $T$ & $P$-value & $\begin{array}{l}\text { Adjusted } \\
P \text {-value }\end{array}$ & $B$-value & Gene name \\
\hline 7906443 & FCER1A & 2.48 & 6.42 & 12.04 & $4.51 \mathrm{E}-15$ & $1.46 \mathrm{E}-10$ & 23.77 & $\begin{array}{l}\text { Receptor for Fc fragment of IgE, alpha } \\
\text { polypeptide }\end{array}$ \\
\hline 8083260 & CPA3 & 1.66 & 5.35 & 10.24 & $6.77 \mathrm{E}-13$ & 1.09E-08 & 19.08 & Carboxypeptidase A3 (mast cell) \\
\hline 7940226 & $\begin{array}{l}\text { MS4A2 } \\
\text { (FCER1B) }\end{array}$ & 1.19 & 4.94 & 9.62 & $4.22 \mathrm{E}-12$ & $3.12 \mathrm{E}-08$ & 17.35 & $\begin{array}{l}\text { Receptor for Fc fragment of IgE, beta } \\
\text { polypeptide }\end{array}$ \\
\hline 7971950 & $\mathrm{DACH} 1$ & -1.54 & 7.03 & -9.58 & $4.81 \mathrm{E}-12$ & $3.12 \mathrm{E}-08$ & 17.23 & Dachshund homolog 1 \\
\hline 8048847 & $\mathrm{HRB}$ & -1.51 & 11.13 & -9.49 & $6.30 \mathrm{E}-12$ & $3.12 \mathrm{E}-08$ & 16.97 & HIV-1 Rev binding protein (AGFG1) \\
\hline 7988672 & HDC & 1.35 & 6.26 & 9.47 & $6.68 \mathrm{E}-12$ & $3.12 \mathrm{E}-08$ & 16.92 & Histidine decarboxylase \\
\hline 8139656 & GRB10 & -2.33 & 7.87 & -9.44 & $7.35 E-12$ & $3.12 \mathrm{E}-08$ & 16.83 & Growth factor receptor-bound protein 10 \\
\hline 8151512 & PAG1 & -1.17 & 9.83 & -9.42 & $7.73 E-12$ & $3.12 \mathrm{E}-08$ & 16.78 & Csk-binding protein \\
\hline 8103094 & NR3C2 & 1.09 & 6.07 & 9.28 & 1.19E-11 & 4.27E-08 & 16.37 & Mineralocorticoid receptor \\
\hline 8129618 & VNN1 & -2.98 & 10.04 & -9.15 & 1.77E-11 & 5.33E-08 & 15.99 & Vanin 1 \\
\hline 8169249 & MID2 & 0.95 & 5.71 & 9.14 & $1.82 \mathrm{E}-11$ & 5.33E-08 & 15.97 & Midline 2 \\
\hline 7956878 & IRAK3 & -1.98 & 10.44 & -9.09 & $2.11 \mathrm{E}-11$ & $5.62 \mathrm{E}-08$ & 15.82 & Interleukin-1 receptor-associated kinase 3 \\
\hline 8106626 & NA & -1.30 & 7.04 & -9.07 & $2.26 \mathrm{E}-11$ & $5.62 \mathrm{E}-08$ & 15.76 & \\
\hline 8169154 & NA & -1.33 & 6.29 & -9.01 & $2.68 \mathrm{E}-11$ & 5.95E-08 & 15.60 & \\
\hline 8105579 & IP011 & -1.58 & 5.35 & -9.00 & $2.76 \mathrm{E}-11$ & 5.95E-08 & 15.57 & Importin 11 \\
\hline 7980381 & TMED8 & -1.25 & 8.43 & -8.98 & $2.95 \mathrm{E}-11$ & 5.96E-08 & 15.51 & Transmembrane emp24 protein \\
\hline 8112896 & ANKRD34B & -2.12 & 6.34 & -8.83 & $4.75 \mathrm{E}-11$ & 9.03E-08 & 15.05 & Ankyrin repeat domain 34B \\
\hline 8103399 & PDGFC & -1.52 & 7.69 & -8.77 & $5.70 \mathrm{E}-11$ & $1.02 \mathrm{E}-07$ & 14.88 & Platelet derived growth factor $\mathrm{C}$ \\
\hline 8044035 & IL18R1 & -2.97 & 8.71 & -8.73 & $6.37 \mathrm{E}-11$ & 1.03E-07 & 14.77 & Interleukin 18 receptor 1 \\
\hline
\end{tabular}




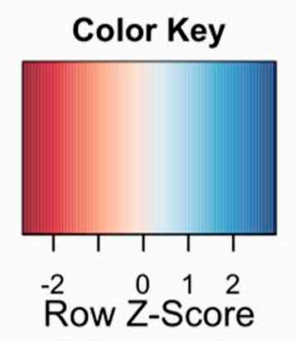

\section{t-test, BactMen}
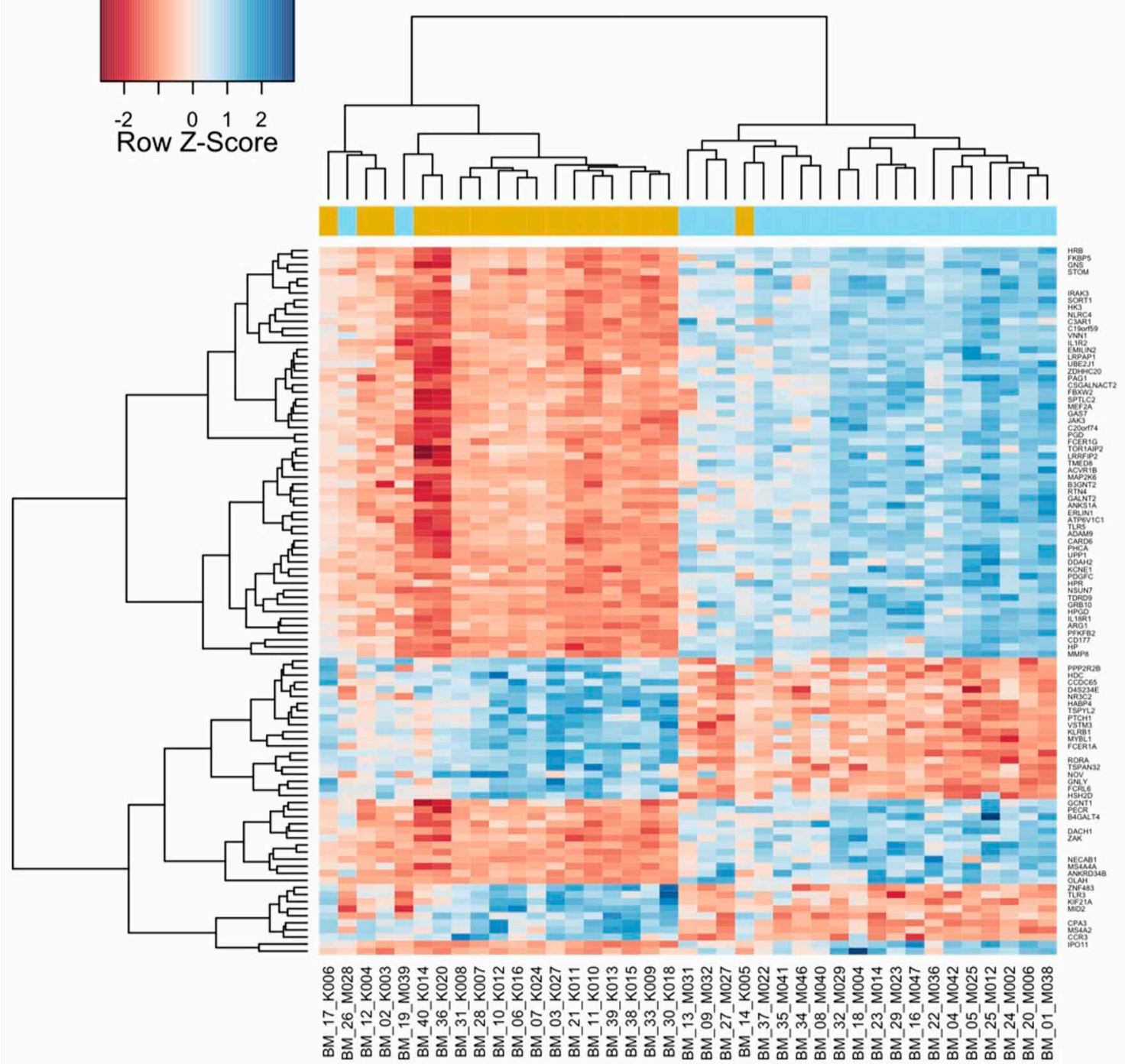

FIGURE 1 | Bacterial meningitis patients have a distinct profile on the heatmap of the blood derived gene expression levels. The top 100 genes (vertical dimension) from the decreasing ordered list of moderated $t$-values were clustered according to the distances between their gene expression values. Signals are scaled to Z-scores of the rows. The colored bar above the heatmap (horizontal dimension) indicates the grouping variable-golden rod for meningitis patients (M), blue for healthy controls $(\mathrm{K})$. pair-wise comparisons between groups were performed. The type of pathogen significantly influenced the expression profile. Table 3 (additional information in Table A3) illustrates gene expression differences if $S$. pneumoniae or other pathogens cause BM. The gene expression profile was significantly different in patients with pneumococcal meningitis compared to BM caused by other pathogens. However, the genes listed in Table 3 differ from the genes responsible for the general effect of BM (BM patients versus controls, see Table 2 ). We have to consider the pathogen heterogeneity here. While the number of patients with $S$. is 14, group with "other" pathogens is smaller (seven patients) and very heterogeneous (almost all pathogens as single entries).
Therefore, this comparison is exploratory without any conclusive outcome.

The clinical outcome was only modestly associated with gene expression profiles, and there were no statistically significant differences ( $p<0.05$ after FDR correction) between groups with a favorable outcome of BM and those with a poor outcome. However, analysis of the separate patient groups with favorable or poor outcome in comparison with healthy controls resulted in significant differences in gene expression profiles that probably reflect the effect of an acute infection.

A functional annotation of expression profiles was subsequently applied in order to identify functional changes in the 


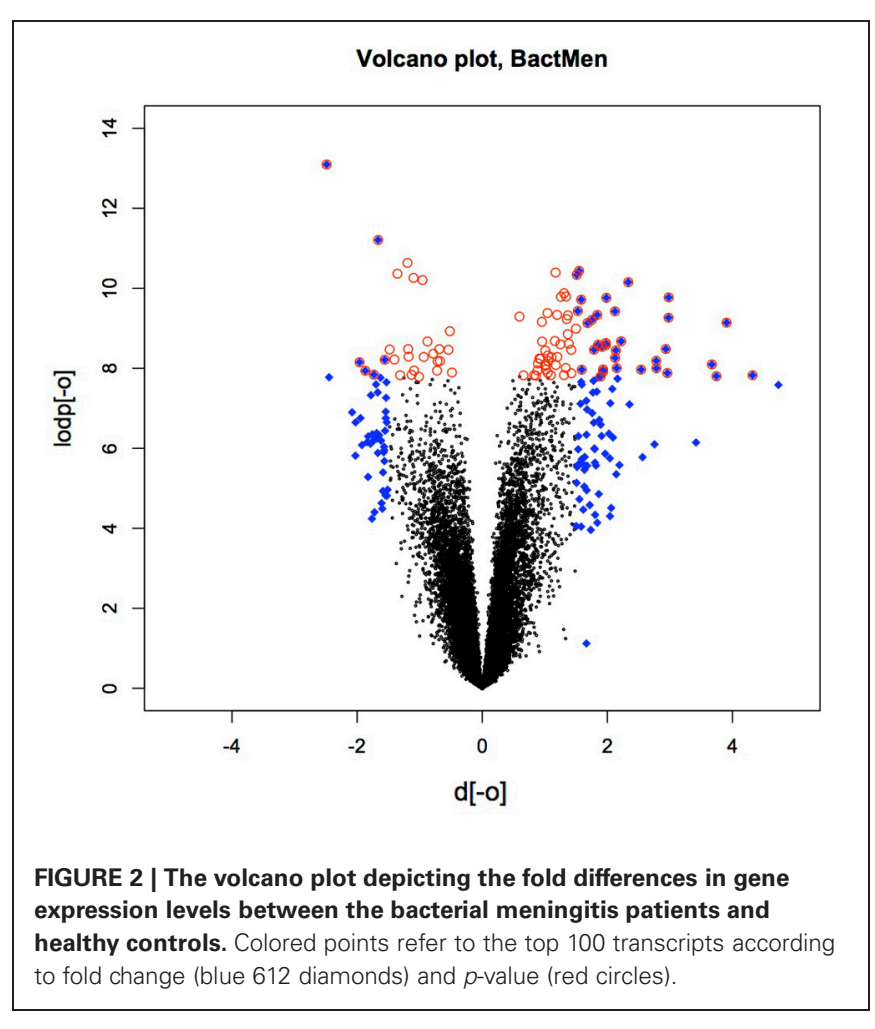

context of genetic networks. Using IPA software, the dataset containing 5500 genes that had significant differential expression between BM and control groups was uploaded. The genetic network with the highest score (43) was related to antigen presentation, cell-mediated and humoral immune response (Table 4). Again, almost all activated networks were related to the immune response.

Maps for the two most significantly disturbed pathways, the antigen presentation and cellular immune response pathways were generated (Figures 3, 4). In the antigen presentation pathway, the up-regulated genes were the major histocompatibility complex (MHC) class II region encoded HLA subgroup genes-HLA-DR, HLA-DQ, HLA-DP. In the case of the cellmediated immune response pathway, the up-regulated genes were associated with interlekins: interleukin-2 receptor subunit beta (IL2RB), interleukin-5 receptor alpha (IL5RA), interleukin-7 receptor (IL7R).

\section{QUANTITATIVE RT-PCR}

In order to verify changes found in the microarray experiment, qRT-PCR was performed. Genes were sorted according to the statistical significance of their differential expression and 10 genes with the lowest $p$-values were selected. The following genes were analyzed: CD177, FCER1A, CPA3, IL1R2, IL18R1, IL18RAP, OLFM4, TLR5, IL5RA, and IL7R. In all 10 cases, qRT-PCR

Table 3 | The type of pathogen caused differences in gene expression profiles and table illustrates comparison between two groups of BM patients, $S$. pneumonia vs. other pathogens.

\begin{tabular}{|c|c|c|c|c|c|c|c|c|}
\hline Probeset & Gene & LogFC & AveExpr & $T$ & $P$-value & $\begin{array}{l}\text { Adjusted } \\
P \text {-value }\end{array}$ & $B$-value & Gene name \\
\hline 7893004 & NA & 2.20 & 4.68 & 5.84 & 7.71E-07 & 0.025 & 5.399 & \\
\hline 7909455 & TRAF3IP3 & 0.76 & 9.28 & 5.02 & 1.09E-05 & 0.085 & 3.136 & TRAF3 interacting protein 3 \\
\hline 8006634 & PIGW & 0.85 & 5.63 & 4.96 & $1.32 \mathrm{E}-05$ & 0.085 & 2.966 & phosphatidylinositol glycan class W \\
\hline 7948894 & RNU2-1 & -2.29 & 6.85 & -4.81 & $2.11 \mathrm{E}-05$ & 0.085 & 2.563 & RNA. U2 small nuclear 1 \\
\hline 7980309 & C14orf1 & 0.66 & 7.73 & 4.70 & 3.04E-05 & 0.085 & 2.251 & probable ergosterol biosynthetic protein 28 \\
\hline 8173269 & LAS1L & 0.63 & 7.04 & 4.63 & 3.83E-05 & 0.085 & 2.052 & LAS1-like \\
\hline 8088458 & FHIT & 0.59 & 6.71 & 4.59 & 4.32E-05 & 0.085 & 1.947 & fragile histidine triad gene \\
\hline 8008517 & NME1 & 0.88 & 6.77 & 4.58 & 4.50E-05 & 0.085 & 1.914 & NME/NM23 nucleoside diphosphate kinase 1 \\
\hline 7899253 & ZDHHC18 & -0.80 & 10.42 & -4.53 & $5.11 \mathrm{E}-05$ & 0.085 & 1.803 & zinc finger. DHHC-type containing 18 \\
\hline 8094719 & N4BP2 & 1.09 & 6.73 & 4.53 & $5.18 \mathrm{E}-05$ & 0.085 & 1.791 & NEDD4 binding protein 2 \\
\hline 7892556 & NA & 0.76 & 12.28 & 4.52 & 5.39E-05 & 0.085 & 1.758 & \\
\hline 7894790 & NA & 0.66 & 9.69 & 4.51 & $5.48 \mathrm{E}-05$ & 0.085 & 1.743 & \\
\hline 7978132 & IPO4 & 0.46 & 7.22 & 4.47 & $6.29 \mathrm{E}-05$ & 0.085 & 1.624 & importin 4 \\
\hline 7972548 & GPR18 & 1.07 & 6.55 & 4.46 & $6.46 \mathrm{E}-05$ & 0.085 & 1.601 & G protein-coupled receptor 18 \\
\hline 7927876 & TET1 & 0.64 & 5.19 & 4.45 & $6.63 \mathrm{E}-05$ & 0.085 & 1.579 & tet oncogene 1 \\
\hline 7930148 & SFXN2 & 0.68 & 6.64 & 4.44 & $6.78 \mathrm{E}-05$ & 0.085 & 1.560 & sideroflexin 2 \\
\hline 7903920 & CHI3L2 & 1.30 & 6.05 & 4.44 & $6.81 \mathrm{E}-05$ & 0.085 & 1.556 & chitinase 3-like 2 \\
\hline 8058670 & IKZF2 & 1.27 & 6.10 & 4.44 & $6.86 \mathrm{E}-05$ & 0.085 & 1.549 & IKAROS family zinc finger 2 \\
\hline
\end{tabular}


Table 4 | Top 10 most significantly activated pathways.

\begin{tabular}{llc}
\hline ID & Molecules in network & Score \\
\hline 1 & AIM2, B3GNT5, BPI, C4, C3AR1, CARD6, CD27, CD63, CD74, CEACAM8, CLEC2D & 43 \\
(includes EG:29121), CRISP3 (includes EG:10321), CST7, EMR1, ETS, HLA-DMA, \\
HLA-DMB, HLA-DPA1, HLA-DPB1, HLA-DQA1, HLA-DRA, IFN Beta, IL12, IL32, \\
IL18R1, IL18RAP, KLRB1, MHC Class II, MHC II, MHC II-and beta, MHC2 Alpha, \\
MYBL1, NFKB, PTGDR, and SOCS3. \\
\hline $2 \quad$ BMX, CCR4, CD2, CD3, CD4, CD5, CD6, CD8, CD28, CD52, CD247, CD3D, CD3E, \\
CD3G, ERK, FCer1, FCER1A, HDC, HSH2D (includes EG:84941), ICOS, IgE, ITK, \\
MERTK, MS4A2, NFATcomplex, PAG1, PDGFC, PLCgamma, PLCG1, RASGRP1, \\
TCR, TEC/BTK/ITK/TXK/BMX, TXK, VAV, and ZAP70. \\
\hline $3 \quad$ ARG1, ARHGAP29, Calpain, CCL5, CCR7, CD3-TCR, CD40LG, CLC, CYP1B1, \\
FGD4, Filamin, FLOT1, GNLY, GZMB, HPR, IgG, IgM, Integrin and alpha, ITGA4, \\
ITGA7, ITGAM, ITGB7, Jnk, KLHL2, LRG1, MAP2K1/2, MMP, MMP8, MTF1, POR, \\
PRF1, Rap1, Ras homolog, SAMSN1, and Tgf beta.
\end{tabular}
4 ADM, Alcohol group acceptor phosphotransferase, BCL2A1, Calcineurin protein(s), CDC25B, Cpla2, Creb, CX3CR1, DPP4, GBA, GPR183, GZMA, hCG, HGF, HMGB2, Hsp27, IL1RL1, LDHA, LDHB, LDL, MAP2K6, MAPK14, Mek, MKK3/6, MKNK1, MS4A1, NFATC2, P38 MAPK, PRKCH, PRKCQ,R PS6KA5, Rsk, TNFAIP6, Vegf, and ZAK.

5 AIM2, ANKS1A, ARG1, ARG2, Arginase, BTN3A1, BTN3A2, CD163, CLEC4E, CLEC5A, CYSLTR1, CYSLTR2, EIF1AY, GAS7, HLX, IFI44, IFI44L, IFNA2, IFNG, IGF1, IL13, IL13RA2, IL18R1, IL18RAP, IL4R, ISL1, LCN2, MS4A4A, P2RY5, PDLIM2, PECR, SAMSN1, SLC1A3, TRPS1, and UBD.

$35 \quad 23$

Focus molecules 26 6

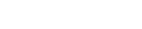

(2)

\section{Top functions}

Antigen presentation, cell-mediated immune response, and humoral immune response.
$25 \quad$ Cell signaling, molecular transport, and vitamin and mineral metabolism.
$23 \quad$ Cell-to-cell signaling and interaction, hematological system development and function, and immune cell trafficking.
Cellular compromise, inflammatory disease, and genetic disorder.

6 Akt, CD163, CR1, FLT3, GC-GCR dimer, GRB10, Ifn gamma, IKK, IL1, IL-1R, IL-1R/TLR, IL1R1, IL1R2, IL2RB, IL5RA, IL7R, Interferon alpha, IRAK3, IRF, JUN/JUNB/JUND, KCNA3, LCN2, NEDD4, NF-and kappa; B, ORM1, Ptk, RARRES3, RNF125, SIGLEC5, STAT5a/b, TGFBR3, TIFA, TIr, TLR2, and TLR5.

$33 \quad 22$

Antigen presentation, cell-mediated immune response, and humoral immune response.

\begin{tabular}{|c|c|c|}
\hline 31 & 21 & $\begin{array}{l}\text { Cell-mediated immune } \\
\text { response, hematological syst } \\
\text { development and function, ar } \\
\text { tissue morphology. }\end{array}$ \\
\hline $\begin{array}{l}\text { me c, } \\
\text { PARG, }\end{array}$ & 20 & $\begin{array}{l}\text { Cardiovascular disease, } \\
\text { hematological disease, and } \\
\text { neurological disease. }\end{array}$ \\
\hline
\end{tabular}
7 ACSL1, Actin, AMPK, CASP5, Caspase, CCNA1, CCND2, Cyclin A, Cytochrome c, $29 \quad 20 \quad$ Cardiovascular disease, DACH1, E2f, ERK1/2, Erm, GZMK, Histone h3, Hsp70, Hsp90, IFIT1, Insulin, hematological disease, and KCNMA1, KLRG1, MME, MMP9, NFKBIA, NLRC4, NR3C2, PFKFB3, PI3K, PPARG, neurological disease. RNA polymerase II, SPN, STAT, TNFAIP3, TRAT1, and VNN1.
8 Ap1, ARL4C, B4GALT4, B4GALT5, CAMK4, CaMKII, CCR3, CEACAM1, CHI3L1, Coup-Tf, ETS1, ETS2, G alphai, GADD45A, Galactosyltransferase beta 1,4, HPGD, HRH4, LRRN3, LTF, Mapk, Myosin, Nfat, PADI4, Pak, Pdgf, PDGF BB, PFKFB2, PLEKHA1, PP2A, Rac, Rxr, SERPINB1, THBS1, VitaminD3-VDR-RXR, and WDFY3.

$\begin{array}{ll}2620 \quad & \text { Gene expression, cardiovascular } \\ & \text { system development and } \\ & \text { function, and cellular } \\ & \text { movement. }\end{array}$

9 24,25-dihydroxyvitamin D3, ACVR1B, ADCYAP1R1, ALP, ALPL, ASPH, ATP9A, CA4, Calmodulin, CD84, CD244, Ck2, CYP19A1, CYP2D6, DDAH2, F Actin, FSH, GPR56, LY9, Pka, Pkc(s), PLC, PRKACB, PRKACG, Proteasome, Ras, SH2D1A, SH2D1B, SH3BP4, SLAMF6, SLAMF7, SMPDL3A, STAT4, TCF7, and UPP1. morphology.
10 ATP13A3 (includes EG:79572), CALML3, CCNG2, CCR7, CD59, CD177, CD274, CEP170, CSF3, ENTPD7, GALNT14, GYG1, IDI1, IL17F, IL1RAPL1, LRRFIP2, MS4A5, MUC2, MUC13, MUC5AC, MYO10, NCR3, NR1D1, NR1D2, PCOLCE2, PIGA, PLEKHA6, PRTN3, RORA, SH3BGRL2, SORL1, TGFB1, TMED8, UBE2J1, and ZFP36.

$20 \quad 15$
15 5 Hematological disease, cell disease.

confirmed statistically significant changes in gene expression between the groups (Figure 5). In BM patients, CPA3, FCER1A, IL5RA, and IL7R were up-regulated and IL18R1, IL18RAP, OLFM4, TLR5, CD177, and IL1R2 were down-regulated.

\section{DISCUSSION}

The significant role of the immune response in determining the outcome of BM has been well characterized in the literature. The present exploratory study on gene profiling in patients 


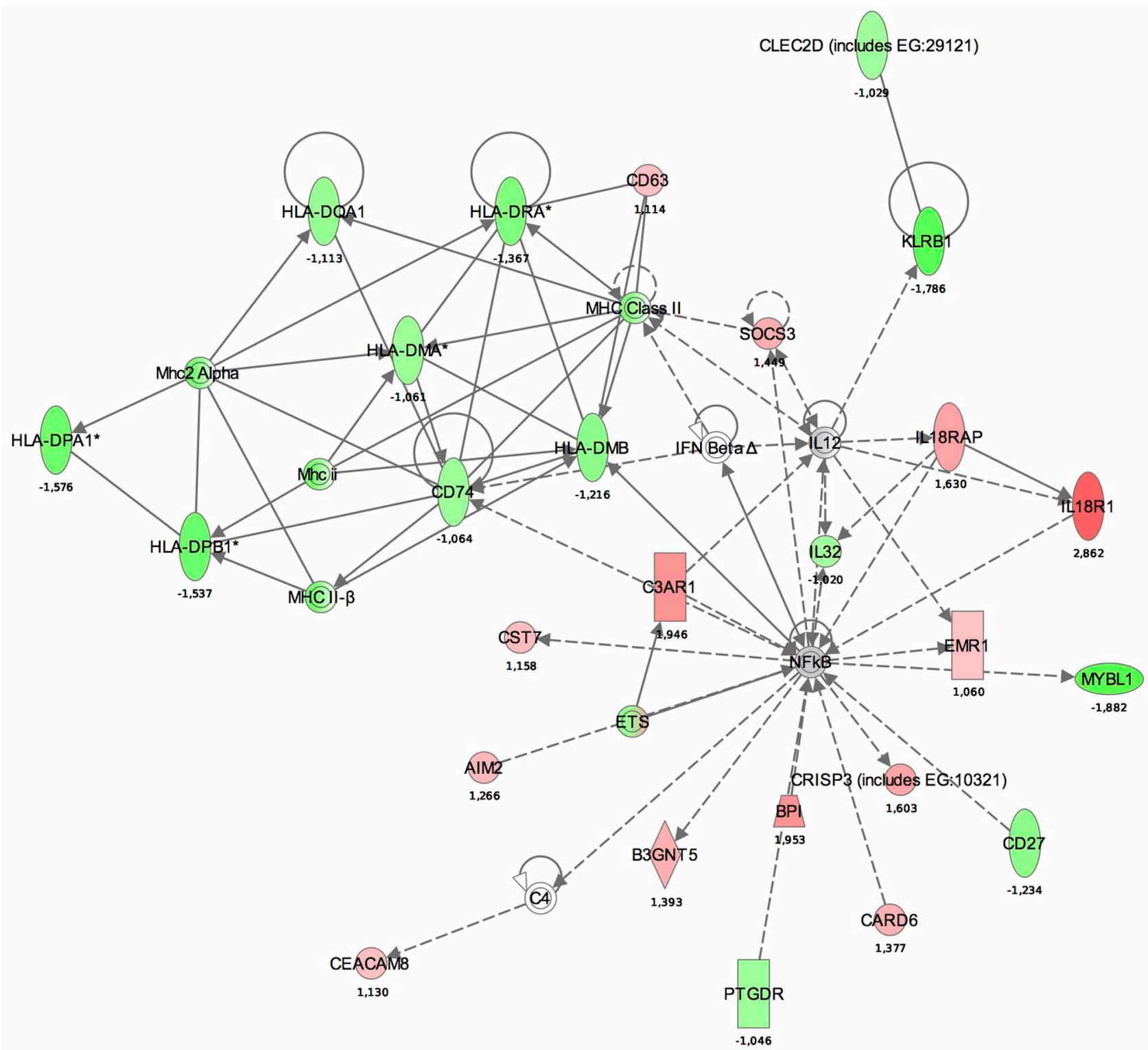

FIGURE 3 | Functional analysis of the gene expression networks, performed using Ingenuity Pathway Analysis (IPA). This figure illustrates the activation of the antigen presentation pathway. The genes in green were down-regulated and the genes in red were up-regulated with respect to the healthy control group. (Numbers are fold changes). with $\mathrm{BM}$ demonstrates that activation of the host's immune response occurs at the level of the transcriptome. Most of the up-regulated genes are derived from mast cells suggesting hyper-activation of the immune system and allergic response (Saito, 2008; Manikandan et al., 2012). However, there are still many significantly up- or down-regulated genes which have not been clearly associated with bacterial infections to date. As no other genome-wide gene expression profiling studies have been done in BM patients, we compared our results with earlier studies conducted on sepsis patients (Stone, 1994; Warren, 1997; Hotchkiss and Karl, 2003; Nduka and Parrillo, 2009).

In the early phase of sepsis, a full-blown activation of immune responses due to the release of high levels of damage associated molecular patterns (DAMPs) from invading microorganisms or damaged host tissue has been described. This leads to up-regulation of TLR expression (Nduka and Parrillo, 2009). Activation of TLR2 and TLR4 are some of the first steps in the immune response to $\mathrm{BM}$, triggering the inflammatory cascade by the cytokines (Coimbra et al., 2006; Manikandan et al., 2012). Our findings on a systemic response to infection are quite general as the group of BM patients in our study was quite heterogeneous, with a wide range of ages and infecting organisms. As a general or common pattern for the BM, we found a significant activation of inflammatory and immune response genes. Common or general patterns in mammalian cell transcriptome response to pathogens causing meningitis have been described (Schubert-Unkmeir et al., 


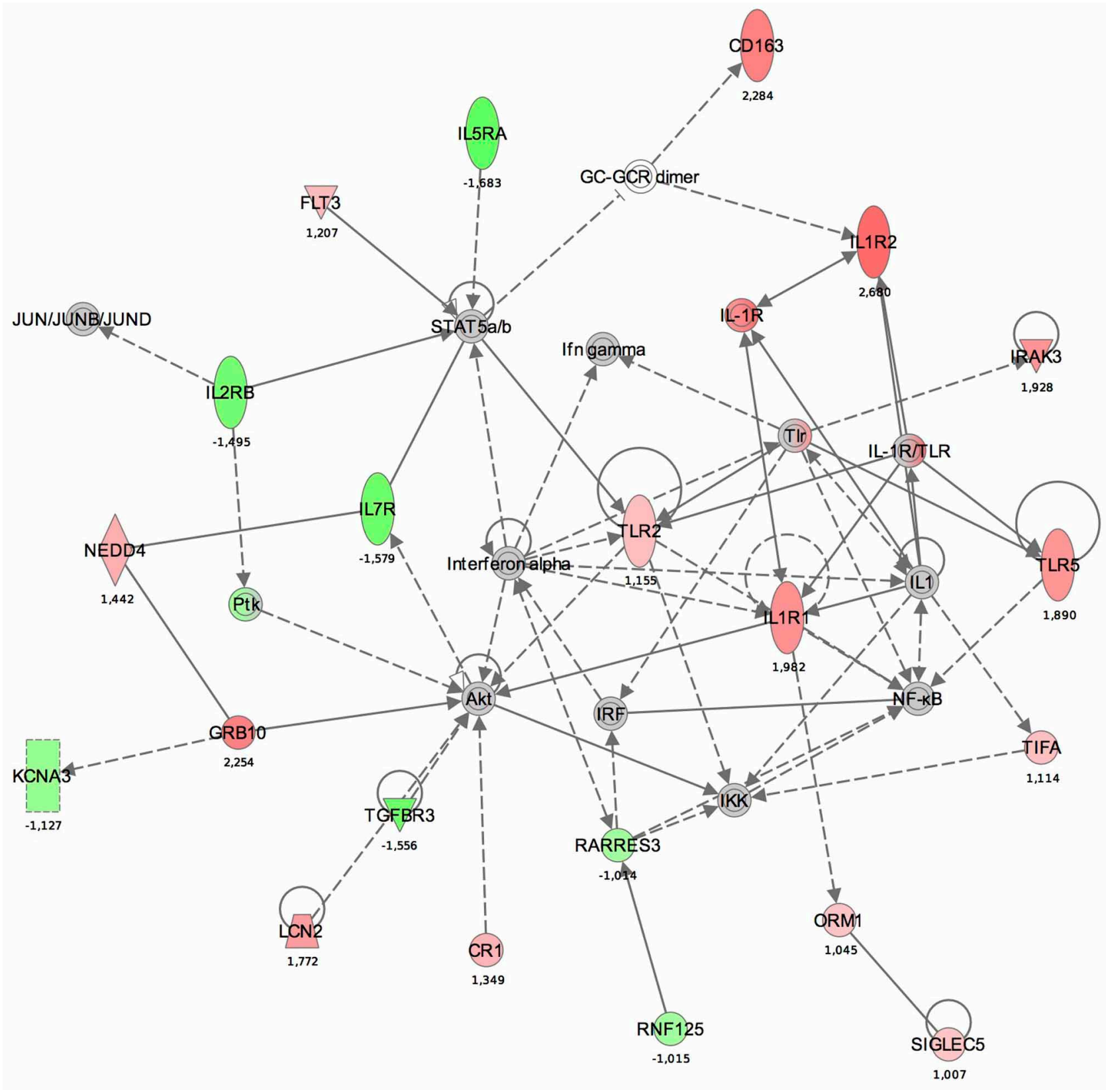

FIGURE 4 | The functional analysis of the gene expression networks, performed using Ingenuity Pathway Analysis (IPA). This figure illustrates the activation of the cell-mediated immune response network. Genes in green were down-regulated and the in red were up-regulated with respect to the healthy control group. (Numbers are fold changes).
2009). Immune activation with up-regulation of interleukins and interferons has been accepted as a general response to meningitis (Schubert-Unkmeir et al., 2009). However, the results in literature and the design of these experiments are quite different. While several studies have described activation of different components of the immune response, other studies have used animal models or ex vivo blood samples, no systemic whole transcriptome analysis of blood samples from BM patients has been performed so far (Pathan et al., 2004; Schubert-Unkmeir et al., 2009; Del Tordello et al., 2012). Therefore, our study describes a unique approach, analyzing blood samples of BM patients for whole genome transcription profiling.

In addition to the general pattern, we found some pathogen specific footprints in the gene expression profile in single cases. Cluster analysis of these gene expression profiles demonstrated that the only case of E. coli meningitis in the 17 days old baby (BM_19_M039) clustered within the control group (Figure 1). Whether this is due to the fact that the blood gene expression profile is pathogen specific or because this case occurred in a neonate, or both, remains to be proven in larger studies. Another 


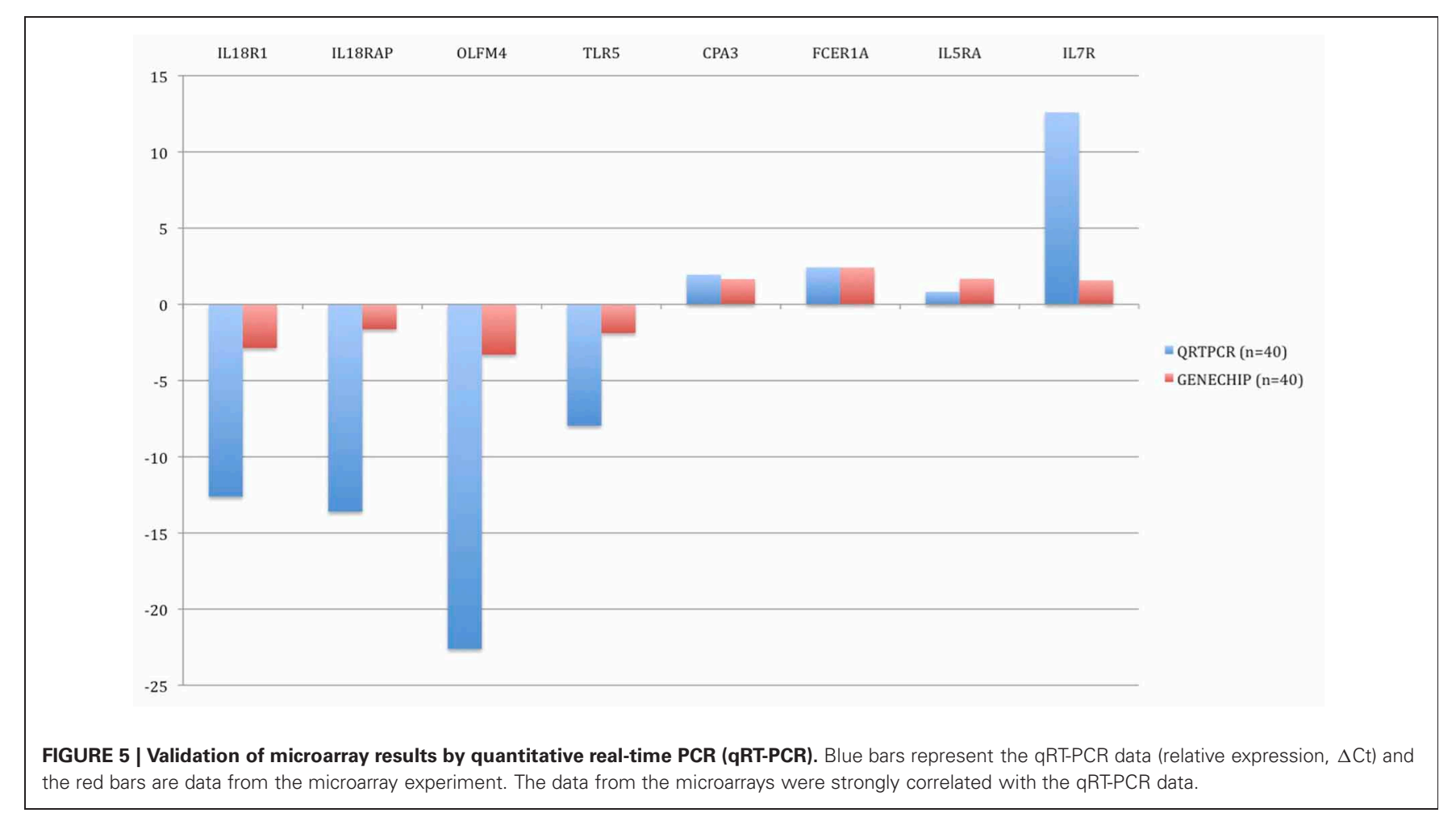

case of neonatal meningitis clustering among the controls had a new episode of BM few weeks later. This may have been indicative of an abnormal immune response in that child. Previous antimicrobial therapy was not associated with clustering. Both patients (BM_19_M039 and BM_26_M028) were children with an age less than one month but the age cannot be the only reason for different clustering as the third, very young patient did not show a similar gene expression profile to BM_19_M039 and BM_26_M028. Differential clustering was also supported in the analysis using a linear model, where a significant effect of pathogen type was found on the differential expression.

All the samples were collected from the patients during hospitalization, during the acute phase of the disease. Therefore, expression of the genes related to pathogen identification and pro- and anti-inflammatory cellular signaling was expected to be increased (Coimbra et al., 2006). In addition to common immune system activation genes (interleukins etc.), we were able to see quite specific hypersensitivity-related gene expression pattern, not described for BM so far. Indeed, the three most up-regulated genes were FCER1A, CPA3, and MS4A2, all closely related to the early immune response and hypersensitivity. FCER1A is involved in inducing the inflammatory and immediate hypersensitivity responses in allergic disorders such as hay fever, asthma, and chronic idiopathic urticaria (Bleehen et al., 1987; Bruhn, 2011; Chandrashekhar et al., 2011; Rueff et al., 2011). FCER1A seems to play a role in several pathways involved in both innate and adaptive immune responses (Van Vugt et al., 1996, 1999; Ernst et al., 1998; Edberg et al., 1999). CPA3, mast cell carboxypeptidase, is a distinctive carboxypeptidase which is exclusively located in mast cells and possesses pancreatic carboxypeptidase A (CPA)like activity (Goldstein et al., 1989; Natsuaki et al., 1992). MS4A2
(FCER1B) plays a role in allergic or autoimmune diseases, such like Wegener's granulomatosis, asthma and atopic dermatitis (Grammatikos, 2008; Mathias et al., 2009; Sanak et al., 2009). Therefore, the list of up-regulated genes suggests a strong activation of the anaphylactic response genes and mast cells in addition to the immune system activation. This finding could explain the complicated clinical course of BM. Immune response factors can be deleterious to the functions of an organism. Interleukin 6 has been shown to cause myocardial dysfunction during meningococcal septic shock (Pathan et al., 2004). Interestingly, activation of mast cells is not necessary deleterious as mast cells can increase survival in certain sepsis models (Piliponsky et al., 2008).

Similar to studies on systemic response (Schubert-Unkmeir et al., 2009; Echenique-Rivera et al., 2011), we also observed networks with functions including "Antigen presentation," "Cell signaling," "Cell-mediated immune response," and "Humoral immune response" among the top activated pathways. In the antigen presentation pathway, the up-regulated genes were MHC class II region encoded HLA subgroup genes-HLA-DR, -DQ, -DP. The MHC-II locus consists of a group of 7-10 highly polymorphic genes that code for the alpha and beta chains of the classical MHC-II heterodimeric molecules. These molecules function by presenting antigenic peptides to $\mathrm{CD} 4+\mathrm{T}$ lymphocytes and are critical in the development of the $\mathrm{T}$ cell repertoire, proliferation and differentiation of antigen-specific CD4+ T cells during adaptive immune responses. HLA-DM, also present in our pathway aids this process, as it is a MHC class-II-associated molecule (Majumder et al., 2006).

In the antigen presentation pathway, down-regulated genes were IL18R1 and IL18RAP. IL18R is a key regulator of TH1 cells. Binding of $\mathrm{IL}-18$ to $\mathrm{IL}-18 \mathrm{R}$ stimulates $\mathrm{TH} 1$ but also 
TH2-type cytokine release depending on its cytokine milieu. A strong association between a single-nucleotide polymorphism (SNP) located in IL18R1 and asthma and atopic phenotypes has been recently observed (Reijmerink et al., 2008).

In the cell-mediated immune response pathway, the following genes were up-regulated: IL2RB, IL5RA, IL7R. The IL2RB protein is expressed in large granular lymphocytes (LGL) in their resting state. This beta subunit is involved in receptor mediated endocytosis and transduces the mitogenic signals of IL2 (http:// www.genecards.org). Interleukin 5 receptor alpha (IL5RA) is an IL5 receptor and binds to IL5. Anti-inflammatory cytokines, including IL10, IL4, IL13, and IL5, are synthesized from Th2 immune cells. It has been found that increased expression of IL5RA on CD34+ cells favors eosinophilopoesis and therefore may contribute to the subsequent development of blood and tissue eosinophilia, a hallmark of allergic inflammation (Sehmi et al., 1997).

Some limitations of the study should be noted. Due to the rarity of BM, the patients group is very small and heterogeneous in terms of age and infecting organisms. Heterogeneity of our study populations makes our study non-conclusive and this is a serious limitation. Children were not included into the control group, so those two groups were not completely age-matched and they differed in the lower quartile for age (47 and 13). Also, heatmap (Figure 1) clearly shows that the two newborns cluster to the controls and third newborn clusters to the meningitis group. Therefore, we cannot exclude possible age-dependent effects.

In addition, pathogen specific subgroup analysis is also complicated. In our study we mainly had patients with S. pneumoniae and very few patients infected with other pathogens. At the

\section{REFERENCES}

Bleehen, S. S., Thomas, S. E., Greaves, M. W., Newton, J., Kennedy, C. T., Hindley, F., et al. (1987). Cimetidine and chlorpheniramine in the treatment of chronic idiopathic urticaria: a multi-centre randomized double-blind study. Br. J. Dermatol. 117, 81-88.

Bone, R. C., Balk, R. A., Cerra, F. B., Dellinger, R. P., Fein, A. M., Knaus, W. A., et al. (1992). Definitions for sepsis and organ failure and guidelines for the use of innovative therapies in sepsis. The ACCP/SCCM Consensus Conference Committee. American College of Chest Physicians/Society of Critical Care Medicine. Chest 101, 1644-1655.

Bruhn, C. (2011). [Mast cells - more than allergy mediators. News from mast cell research]. Med. Monatsschr. Pharm. 34, 206-208.

Chandrashekhar, V. M., Halagali, K. S., Nidavani, R. B., Shalavadi, M. H., Biradar, B. S., Biswas, D., et al. (2011). Anti-allergic activity of German chamomile (Matricaria recutita $L$.) in mast cell mediated 137, 336-340.

same time the "other pathogens" group was very heterogeneous. Therefore, results from pathogen comparison should be treated with caution.

Moreover, our analysis was based on the RNA extracted from the whole blood, not from the enriched Peripheral Blood Monocyte Cells (PBMCs) fraction. We acknowledge that the composition of the circulating blood cells in patients with BM and healthy controls is very different and that analysis of PBMCs would give a more focused description of the transcriptome. However, the whole blood may even be more advantageous as PBMCs reduce the number of neutrophils and in the case on $\mathrm{BM}$, gene expression patterns from neutrophils may dominate the gene expression profile (Del Tordello et al., 2012; Li et al., 2012). Therefore, the analysis of the whole blood may present a more complete and systemic picture of changes in the blood transcriptome.

Our findings from the genome-wide expression profiling study indicate that there is a significant immune activation at the level of the transcriptome in patients with BM and we suggest that this could partly explain the complicated clinical course and poor outcome of BM. However, these findings are not conclusive due to the limited size and heterogeneity of our samples and should be verified in studies using a larger sample size and more homogeneous or matched population.

\section{ACKNOWLEDGMENTS}

The financial support by Estonian Science Foundation (grant ETF7408) is acknowledged. The European Regional Development Fund together with the Archimedes Foundation supported this study.

human blood using a tiling array. J. Bacteriol. 194, 6217-6232.

allergy model. J. Ethnopharmaco

Chaudhuri, A., Martinez-Martin, P., Kennedy, P. G., Andrew Seaton, R., Portegies, P., Bojar, M., et al. (2008). EFNS guideline on the management of community-acquired bacterial meningitis: report of an EFNS Task Force on acute bacterial meningitis in older children and adults. Eur. J. Neurol. 15, 649-659.

Coimbra, R. S., Voisin, V., De Saizieu, A. B., Lindberg, R. L., Wittwer, M., Leppert, D., et al. (2006). Gene expression in cortex and hippocampus during acute pneumococcal meningitis. BMC Biol. 4:15. doi: 10.1186/1741-7007-4-15

Deisenhammer, F., Bartos, A., Egg, R., Gilhus, N. E., Giovannoni, G., Rauer, S., et al. (2006). Guidelines on routine cerebrospinal fluid analysis. Report from an EFNS task force. Eur. J. Neurol. 13, 913-922.

Del Tordello, E., Bottini, S., Muzzi, A., and Serruto, D. (2012). Analysis of the regulated transcriptome of Neisseria meningitidis in
Echenique-Rivera, H., Muzzi, A., Del Tordello, E., Seib, K. L., Francois, P., Rappuoli, R., et al. (2011). Transcriptome analysis of Neisseria meningitidis in human whole blood and mutagenesis studies identify virulence factors involved in blood survival. PLoS Pathog. 7:e1002027. doi: 10.1371/journal.ppat.1002027

Edberg, J. C., Yee, A. M., Rakshit, D. S. Chang, D. J., Gokhale, J. A., Indik, Z. K., et al. (1999). The cytoplasmic domain of human FcgammaRIa alters the functional properties of the FcgammaRI.gamma-chain receptor complex. J. Biol. Chem. 274, 30328-30333.

Ernst, L. K., Duchemin, A. M., Miller, K. L., and Anderson, C. L. (1998). Molecular characterization of six variant Fcgamma receptor class I (CD64) transcripts. Mol. Immunol. 35, 943-954.

Fassbender, K., Schminke, U., Ries, S., Ragoschke, A., Kischka, U., Fatar, M., et al. (1997). Endothelial-derived adhesion molecules in bacterial meningitis: association to cytokine release and intrathecal leukocyte-recruitment. J. Neuroimmunol. 74, 130-134.

Goldstein, S. M., Kaempfer, C. E., Kealey, J. T., and Wintroub, B. U. (1989). Human mast cell carboxypeptidase. Purification and characterization. J. Clin. Invest. 83, 1630-1636.

Grammatikos, A. P. (2008). The genetic and environmental basis of atopic diseases. Ann. Med. 40, 482-495.

Hotchkiss, R. S., and Karl, I. E. (2003). The pathophysiology and treatment of sepsis. N. Engl. J. Med. 348, 138-150.

Koedel, U., Angele, B., Rupprecht, T., Wagner, H., Roggenkamp, A., Pfister, H. W., et al. (2003). Toll-like receptor 2 participates in mediation of immune response in experimental pneumococcal meningitis. J. Immunol. 170, 438-444.

Konat, G. W., Kielian, T., and Marriott, I. (2006). The role of Toll-like receptors in CNS response to microbial challenge. J. Neurochem. 99, 1-12.

Li, P., Bai, J., Li, J. X., Zhang, G. L., Song, Y. H., Li, Y. F., et al. (2012). 
Molecular cloning, sequencing, and expression of the outer membrane protein P2 gene of Haemophilus parasuis. Res. Vet. Sci. 93, 736-742.

Majumder, P., Gomez, J. A., and Boss, J. M. (2006). The human major histocompatibility complex class II HLA-DRB1 and HLADQA1 genes are separated by a CTCF-binding enhancer-blocking element. J. Biol. Chem. 281, 18435-18443.

Manikandan, J., Kothandaraman, N., Hande, M. P., and Pushparaj, P. N. (2012). Deciphering the structure and function of FcepsilonRI/mast cell axis in the regulation of allergy and anaphylaxis: a functional genomics paradigm. Cell. Mol. Life Sci. 69, 1917-1929.

Mathias, C. B., Freyschmidt, E. J., Caplan, B., Jones, T., Poddighe, D., Xing, W., et al. (2009). IgE influences the number and function of mature mast cells, but not progenitor recruitment in allergic pulmonary inflammation. J. Immunol. 182, 2416-2424.

Natsuaki, M., Stewart, C. B., Vanderslice, P., Schwartz, L. B., Natsuaki, M., Wintroub, B. U., et al. (1992). Human skin mast cell carboxypeptidase: functional characterization, cDNA cloning, and genealogy. J. Invest. Dermatol. 99, 138-145.

Nduka, O. O., and Parrillo, J. E. (2009). The pathophysiology of septic shock. Crit. Care Clin. 25, 677-702.

Neher, J. J., and Brown, G. C. (2007). Neurodegeneration in models of Gram-positive bacterial infections of the central nervous system. Biochem. Soc. Trans. 35, 1166-1167.
Pathan, N., Hemingway, C. A., Alizadeh, A. A., Stephens, A. C., Boldrick, J. C., Oragui, E. E., et al. (2004). Role of interleukin 6 in myocardial dysfunction of meningococcal septic shock. Lancet 363, 203-209.

Piliponsky, A. M., Chen, C. C., Nishimura, T., Metz, M., Rios, E. J., Dobner, P. R., et al. (2008). Neurotensin increases mortality and mast cells reduce neurotensin levels in a mouse model of sepsis. Nat. Med. 14, 392-398.

Reijmerink, N. E., Postma, D. S., Bruinenberg, M., Nolte, I. M., Meyers, D. A., Bleecker, E. R., et al. (2008). Association of IL1RL1, IL18R1, and IL18RAP gene cluster polymorphisms with asthma and atopy. J. Allergy Clin. Immunol. 122, 651-654. e658.

Rueff, F., Friedl, T., Arnold, A., Kramer, M., and Przybilla, B. (2011). Release of mast cell tryptase into saliva: a tool to diagnose food allergy by a mucosal challenge test? Int. Arch. Allergy Immunol. 155, 282-288.

Saito, H. (2008). Progress in allergy signal research on mast cells: systemic approach to mast cell biology in allergic diseases. J. Pharmacol. Sci. 106, 341-346.

Sanak, M., Potaczek, D. P., Sznajd, J., Musial, J., and Szczeklik, A. (2009). Genetic associations of variants of the high affinity receptor for immunoglobulin E in Wegener's granulomatosis. Pol. Arch. Med. Wewn. 119, 170-174.

Schubert-Unkmeir, A., Slanina, H., and Frosch, M. (2009). Mammalian cell transcriptome in response to meningitis-causing pathogens. Expert Rev. Mol. Diagn. 9, 833-842.
Sehmi, R., Wood, L. J., Watson, R., Foley, R., Hamid, Q., O’Byrne, P. M., et al. (1997). Allergeninduced increases in IL-5 receptor alpha-subunit expression on bone marrow-derived CD34+ cells from asthmatic subjects. A novel marker of progenitor cell commitment towards eosinophilic differentiation. J. Clin. Invest. 100 2466-2475.

Smyth, G. K. (2004). Linear models and empirical bayes methods for assessing differential expression in microarray experiments. Stat. Appl. Genet. Mol. Biol. 3:3. doi: 10.2202/1544-6115.1027

Stone, R. (1994). Search for sepsis drugs goes on despite past failures. Science 264, 365-367.

Storey, J. D., and Tibshirani, R. (2003). Statistical significance for genomewide studies. Proc. Natl. Acad. Sci. U.S.A. 100, 9440-9445.

Trojano, M., Avolio, C., Simone, I. L., Defazio, G., Manzari, C., De Robertis, F., et al. (1996). Soluble intercellular adhesion molecule-1 in serum and cerebrospinal fluid of clinically active relapsing-remitting multiple sclerosis: correlation with Gd-DTPA magnetic resonance imaging-enhancement and cerebrospinal fluid findings. Neurology 47, 1535-1541.

Van Vugt, M. J., Heijnen, A. F., Capel, P. J., Park, S. Y., Ra, C., Saito, T., et al. (1996). FcR gamma-chain is essential for both surface expression and function of human $\mathrm{FC}$ gamma RI (CD64) in vivo. Blood 87 , 3593-3599.

Van Vugt, M. J., Kleijmeer, M. J., Keler, T., Zeelenberg, I., Van Dijk, M. A., Leusen, J. H., et al. (1999). The FcgammaRIa (CD64) ligand binding chain triggers major histocompatibility complex class II antigen presentation independently of its associated FcR gamma-chain. Blood 94, 808-817.

Warren, H. S. (1997). Strategies for the treatment of sepsis. N. Engl. J. Med. 336, 952-953.

Weisfelt, M., De Gans, J., Van Der Poll, T., and Van De Beek, D. (2006). Pneumococcal meningitis in adults: new approaches to management and prevention. Lancet Neurol. 5, 332-342.

Conflict of Interest Statement: The authors declare that the research was conducted in the absence of any commercial or financial relationships that could be construed as a potential conflict of interest.

Received: 01 February 2013; accepted: 26 February 2013; published online: 18 March 2013.

Citation: Lill M, Kõks S, Soomets U, Schalkwyk LC, Fernandes C, Lutsar I and Taba P (2013) Peripheral blood RNA gene expression profiling in patients with bacterial meningitis. Front. Neurosci. 7:33. doi: 10.3389/fnins.2013.00033

This article was submitted to Frontiers in Neurogenomics, a specialty of Frontiers in Neuroscience.

Copyright (c) 2013 Lill, Kõks, Soomets, Schalkwyk, Fernandes, Lutsar and Taba. This is an open-access article distributed under the terms of the Creative Commons Attribution License, which permits use, distribution and reproduction in other forums, provided the original authors and source are credited and subject to any copyright notices concerning any third-party graphics etc. 


\section{APPENDIX}

Table A1 | Characteristics of the control group used in present study.

\begin{tabular}{lll}
\hline & Age & Sex \\
\hline K003 & 85 & Female \\
K004 & 58 & Female \\
K005 & 81 & Male \\
K006 & 52 & Male \\
K007 & 60 & Female \\
K008 & 40 & Female \\
K009 & 39 & Female \\
K010 & 61 & Female \\
K011 & 48 & Female \\
K012 & 28 & Male \\
K013 & 47 & Female \\
K014 & 58 & Female \\
K015 & 52 & Female \\
K016 & 47 & Female \\
K018 & 60 & Female \\
K020 & 51 & Female \\
K024 & 72 & Male \\
K027 & 56 & Male \\
\hline
\end{tabular}

Table A2 | The function of the most significantly up- and down-regulated genes described in Table 2.

\begin{tabular}{ll}
\hline Genes & Function \\
\hline FCER1A & $\begin{array}{l}\text { This gene encodes the alpha subunit of immunoglobulin } \\
\text { epsilon receptor (lgE receptor), what is the initiator of the } \\
\text { allergic response. It is found on the surface of mast cells } \\
\text { and basophils. }\end{array}$ \\
\hline CPA3 & $\begin{array}{l}\text { Mast cell specific secretory granule metalloexopeptidase } \\
\text { that regulates innate immune response. By degrading } \\
\text { vasoactive peptides, CPA3 is protecting against sepsis } \\
\text { and reduce mortality. }\end{array}$ \\
\hline MS4A2 & $\begin{array}{l}\text { Encodes the beta subunit of immunoglobulin epsilon } \\
\text { receptor (IgE receptor), what is the initiator of the allergic } \\
\text { response. It is found on the surface of mast cells and } \\
\text { basophils. }\end{array}$ \\
\hline DACH1 & $\begin{array}{l}\text { Encodes a chromatin-associated protein that associates } \\
\text { with other DNA-binding transcription factors to regulate } \\
\text { gene expression and cell fate determination during } \\
\text { development. }\end{array}$ \\
\hline HDC & $\begin{array}{l}\text { The encoded protein binds the activation domain of the } \\
\text { human immunodeficiency virus Rev protein when Rev is } \\
\text { assembled onto its RNA target. } \\
\text { histamine. Histamine regulates several physiologic } \\
\text { secretion, inflamation, and smooth muscle tone. }\end{array}$ \\
\hline & $\begin{array}{l}\text { Thid } \\
\text { HRB }\end{array}$ \\
&
\end{tabular}

(Continued)
Table A2 | Continued

\begin{tabular}{|c|c|}
\hline Genes & Function \\
\hline GRB10 & $\begin{array}{l}\text { This gene encodes a growth factor receptor-binding } \\
\text { protein that interacts with insulin receptors and } \\
\text { insulin-like growth-factor receptors. }\end{array}$ \\
\hline PAG1 & $\begin{array}{l}\text { The protein encoded by this gene is involved in the } \\
\text { regulation of } T \text { cell activation. }\end{array}$ \\
\hline NR3C2 & $\begin{array}{l}\text { This gene encodes the mineralocorticoid receptor, which } \\
\text { mediates aldosterone actions on salt and water balance } \\
\text { within restricted target cells. }\end{array}$ \\
\hline VNN1 & This gene may play a role in oxidative-stress response. \\
\hline MID2 & The protein is member of ubiquitin-proteasome system. \\
\hline IRAK3 & $\begin{array}{l}\text { This protein is primarily expressed in monocytes and } \\
\text { macrophages and functions as a negative regulator of } \\
\text { Toll-like receptor signaling and is associated with a } \\
\text { susceptibility to asthma. }\end{array}$ \\
\hline IPO11 & $\begin{array}{l}\text { Importins mediate nucleocytoplasmic transport of protein } \\
\text { and RNA cargoes. }\end{array}$ \\
\hline TMED8 & $\begin{array}{l}\text { Transmembrane emp } 24 \text { protein transport domain } \\
\text { containing } 8 .\end{array}$ \\
\hline ANKRD34B & $\begin{array}{l}\text { A novel phosphoprotein is induced during bone marrow } \\
\text { commitment to dendritic cells. }\end{array}$ \\
\hline PDGFC & $\begin{array}{l}\text { The protein encoded by this gene is a mitogenic factor for } \\
\text { cells of mesenchymal origin. }\end{array}$ \\
\hline IL18R1 & $\begin{array}{l}\text { This receptor specifically binds interleukin } 18 \text { (IL18), and } \\
\text { is essential for IL18 mediated signal transduction, } \\
\text { associated with asthma. }\end{array}$ \\
\hline
\end{tabular}


Table A3 | Function of genes from Table 3 (gene expression profile related to the type of pathogen).

\begin{tabular}{ll}
\hline Genes & Function \\
\hline SEPHS1 & $\begin{array}{l}\text { This gene encodes an enzyme that synthesizes } \\
\text { selenophosphate from selenide and ATP. }\end{array}$ \\
\hline TRAF3IP3 & $\begin{array}{l}\text { The gene encodes a protein that mediates cell growth by } \\
\text { modulating the c-Jun N-terminal kinase signal } \\
\text { transduction pathway. }\end{array}$
\end{tabular}

PIGW Glycosylphosphatidylinositol (GPI) is a complex glycolipid that anchors many proteins to the cell surface.

FOXRED1 The encoded protein is localized to the mitochondria and may function as a chaperone protein required for the function of mitochondrial complex I.

WWC2-AS2 WWC2 antisense RNA 2.

RNU2-1 RNU2-1 forms spliceosome what catalyzes the removal of introns from nuclear mRNA precursors.

C14orf1 Chromosome 14 open reading frame 1 was identified as overexpressed on pancreatic cancer cell lines.

LAS1L LAS1L interacts with the mammalian Rix1 complex to regulate ribosome biogenesis.

FHIT This gene, a member of the histidine triad gene family is involved in purine metabolism.

NME1 This gene (NME1) was identified because of its reduced mRNA transcript levels in highly metastatic cells. It is biomarker of malignancy for some tumors.

TESK2 This gene product is a serine/threonine protein kinase what is involved in sprmatogenesis.

PSMA8 Proteasome subunit.

BYSL Bystin may play multiple roles in mammalian cells, a conserved function is to facilitate ribosome biogenesis required for cell growth.

\begin{tabular}{ll}
\hline ZDHHC18 & Palmitoyltransferase activity. \\
\hline N4BP2 & $\begin{array}{l}\text { This protein binds and hydrolyzes ATP, may function as a } \\
\text { 5'-polynucleotide kinase, and has the capacity to be a } \\
\text { ubiquitylation substrate. }\end{array}$
\end{tabular}

IPO4 Importins 4 and 7 accomplish nuclear import of HIF-1alpha more efficiently than the classical importin alpha/beta NLS receptor.

GPR18 Orphan G-protein-coupled receptor GPR18 with $\mathrm{N}$-arachidonylglycine as the endogenous ligand.

TET1 Tet methylcytosine dioxygenase 1, nuclear exclusion of TET1 is associated with loss of 5-hydroxymethylcytosine in IDH1 wild-type gliomas.

\begin{tabular}{ll} 
HIF-1alpha more efficiently than the classical importin \\
alpha/beta NLS receptor. \\
\hline GPR18 & $\begin{array}{l}\text { Orphan G-protein-coupled receptor GPR18 with } \\
\text { N-arachidonylglycine as the endogenous ligand. }\end{array}$ \\
\hline TET1 & $\begin{array}{l}\text { Tet methylcytosine dioxygenase 1, nuclear exclusion of } \\
\text { TET1 is associated with loss of 5-hydroxymethylcytosine } \\
\text { in IDH1 wild-type gliomas. }\end{array}$
\end{tabular}

(Continued)
Table A3 | Continued

\begin{tabular}{ll}
\hline Genes & Function \\
\hline SFXN2 & $\begin{array}{l}\text { Proteasome related gene, associated with genetic risk for } \\
\text { Parkinson's disease. }\end{array}$ \\
\hline CHI3L2 & $\begin{array}{l}\text { The encoded protein is secreted and is involved in } \\
\text { cartilage biogenesis. }\end{array}$ \\
\hline IKZF2 & $\begin{array}{l}\text { This gene is involved in the regulation of lymphocyte and } \\
\text { in early hematopoietic development. }\end{array}$ \\
\hline
\end{tabular}

